\title{
Perianal and Luminal Relapse Following Perianal Surgical Intervention in Crohn's Disease
}

\author{
Feihong Deng ${ }^{1,2}$ \\ Pianpian Xia ${ }^{1,2}$ \\ Zengrong $\mathrm{Wu} \mathbb{D}^{1,2}$ \\ Hejun Zhou ${ }^{1,2, *}$ \\ Xuehong Wang ${ }^{1,2, *}$ \\ 'Department of Gastroenterology, The \\ Second Xiangya Hospital, Central South \\ University, Changsha, Hunan, 4I00II, \\ People's Republic of China; ${ }^{2}$ Research \\ Center of Digestive Disease, Central \\ South University, Changsha, Hunan, \\ 4I00II, People's Republic of China \\ *These authors contributed equally to \\ this work
}

Background and Aims: Fistula relapse occurs in $20-30 \%$ of patients with perianal Crohn's disease (PCD) despite optimal medico-surgical management. We aimed in this study to assess the rate of perianal and luminal relapse after surgically induced remission and to determine factors associated with fistula relapse.

Methods: Consecutive perianal CD patients who achieved clinical remission after surgery for fistulising PCD from January 2013 to January 2019 were included. The cumulative probabilities of relapse-free survival were estimated using the Kaplan-Meier method.

Results: A total of 130 patients were included. Sixty-six of 130 patients received infliximab (IFX) therapy after perianal surgery. After a median follow-up of 62 months (interquartile range [IQR]: 28-117 months), perianal relapse occurred in 30 of 64 (46.9\%) nonbiological medication-treated cases and in 14 of $66(21.1 \%)$ cases in the IFX therapy group. The cumulative probabilities of perianal relapse-free survival in patients with nonbiological treatment were $77.1 \%$ at 1 year, $54.6 \%$ at 3 years, and $30 \%$ at 5 years. The rates of survival without perianal fistula relapse in the IFX-treated group were $91.6 \%, 69.2 \%$, and $59.3 \%$ at 1,3 and 5 years, respectively. In patients treated with IFX after perianal surgery, discontinuation of IFX therapy (odds ratio $[\mathrm{OR}]=2.43$, $\mathrm{p}=0.036)$, a penetrating $\mathrm{CD}$ phenotype $(\mathrm{OR}=4.324, p=0.019)$, and a complex perianal fistula $(\mathrm{OR}=3.392, p=0.026)$ were independently associated with perianal relapse in multivariate analysis.

Conclusion: Infliximab therapy reduced the risk of perianal relapse after surgical remission in PCD patients compared with nonbiological treatment. However, approximately $40 \%$ of patients using infliximab experienced perianal relapse at 5 years, and patients who discontinued use of IFX or experienced a penetrating phenotype or a complex perianal fistula were associated with increased relapse rate.

Keywords: Crohn's disease, perianal fistula, anti-TNF therapy, infliximab, perianal surgery

\section{Introduction}

Crohn's disease (CD) is a subcategory of inflammatory bowel disease (IBD) that is a chronic, relapsing inflammatory gastrointestinal disorder. ${ }^{1}$ Perianal Crohn's disease (PCD) comprises a common, aggressive and disabling phenotype of $\mathrm{CD}$, presenting in approximately $40 \%$ of patients at the time of diagnosis ${ }^{2}$ and recurring in $20 \%-30 \%$ of patients within 1 year of follow-up. ${ }^{3,4}$ Patients with PCD generally present with increased rates of hospitalization and surgery and a significant reduction in quality of life. ${ }^{5}$

Perianal fistulas in CD are classified as simple or complex. ${ }^{6}$ Simple fistulas are generally treated by fistulotomy without subsequent medical or surgical therapies.
Correspondence: Xuehong Wang Research Center of Digestive Disease, Central South University, Changsha, Hunan, 4I00II, People's Republic of China

Email xuehongwang@csu.edu.cn 
However, complex fistulas with their natural severity often need medico-surgical management. ${ }^{7}$ Surgical drainage of perianal abscesses minimizes the risk of further septic complications and is recommended before medical therapy. ${ }^{8}$ A prospective population-based inception cohort reported that the risk of needing a perianal surgical intervention (PSI) in CD patients was $21 \%$ after 1 year, $38 \%$ after 5 years, and $67 \%$ after 10 years of follow-up, and patients with PCD had a higher rate of abdominal surgery. ${ }^{5}$ Medical therapy, such as antibiotics, immunosuppressants or biologic agents, is an adjuvant to surgery; among them, antibodies targeting tumour necrosis factor (TNF)-alpha are recommended as the first-line medical strategy in PCD. ${ }^{8,9}$

In the biologic era, anti-TNF has become common, and its use significantly improved outcomes in perianal CD patients and reduced the rate of repeat surgery. ${ }^{10}$ Infliximab (IFX) and adalimumab (ADA) are effective both in the induction and maintenance of fistula closure. ${ }^{8}$ A decreased incidence of perianal fistulas was observed in the biologic era (after 1998) compared with the prebiologic era (before 1998). ${ }^{10}$ A study of 94 patients reported a higher response rate in PCD patients treated with IFX compared to placebo ( $68 \%$ versus $26 \%$ ), and the rates of fistula healing were also higher in patients treated with IFX monotherapy (IFX 55\% versus placebo 13\%). ${ }^{11}$ Additionally, the risk of proctectomy among patients who had a perianal fistula decreased from $24 \%$ in the prebiologic era to $13 \%$ in the biologic era. ${ }^{10}$ Furthermore, as $46 \%$ patients who received three IFX infusions (5 $\mathrm{mg} / \mathrm{kg}$ at weeks 0,2 and 6 ) followed by maintenance with an immunomodulator alone experienced CD clinical relapse during the first year of follow-up, longer time use of IFX was recommended in preventing relapse of luminal CD. ${ }^{12-14}$ Moreover, approximately half of patients who received IFX and an antimetabolite agent for at least 1 year for fistulising CD experienced a relapse within 1 year of follow-up after discontinuation of IFX. ${ }^{15}$ Moreover, the recurrence rate of perianal fistula after a 5-year follow-up was not significantly decreased between the prebiologic and biologic eras. ${ }^{16}$ The factors related to perianal fistula relapse in PCD patients receiving biological treatment are still unclarified. The aim of this study was to assess the rate of perianal and luminal relapse after surgically induced remission between IFX and nonbiological treatment and to predict factors associated with fistula relapse.

\section{Methods}

\section{Study Population}

The present study is a retrospective single-centre study that was conducted in the Second Xiangya Hospital, Central South University. Patients (age $\geq 17$ years) who achieved a clinical remission after surgical intervention for fistulising PCD from January 2013 to January 2019 were included. Remission was defined according to the established guidelines as the absence of any draining fistulas during the follow-up visit despite gentle finger compression within 2 months of undergoing an operation to repair a perianal fistula. ${ }^{8,17}$ The follow-up periods started at the time of the last perianal surgery for luminal or perianal fistula recurrence or at the date of the last followup in patients who did not relapse. The follow-up was occurred on June 30, 2020 (Figure 1).

\section{Inclusion Criteria}

1 . are $\geq 17$-years-old;

2. have been diagnosed with perianal CD;

3. were achieved clinical remission after perianal surgery within 2 months

4. without history of colon or rectal surgery

\section{Exclusion Criteria}

1. perianal $C D$ was not confirmed

2. the fistula was unrelated to $C D$

3. patients treated with IFX were less than 3 infusions

4. patients who were not achieved clinical remission after perianal surgery within 2 months

5. previously demonstrated allergy for anti-TNF medication

6. have severe infection such as abdominal abscesses, malignancies, connective tissue disorders including rheumatoid arthritis and systemic lupus erythematosus

The diagnosis of perianal CD was confirmed by established guidelines according to the clinical, endoscopic, biological, radiological, and/or histological evidence. ${ }^{18,19}$ Disease localization and the behaviour of $\mathrm{CD}$ were recorded according to the Montreal classification. Perianal fistulas were classified as simple or complex according to the American Gastroenterological Association classification. ${ }^{6}$ A simple fistula was low in position (superficial or low inter-sphincteric or low transsphincteric origin) and had a single external opening without pain or fluctuation. A complex fistula was defined as 


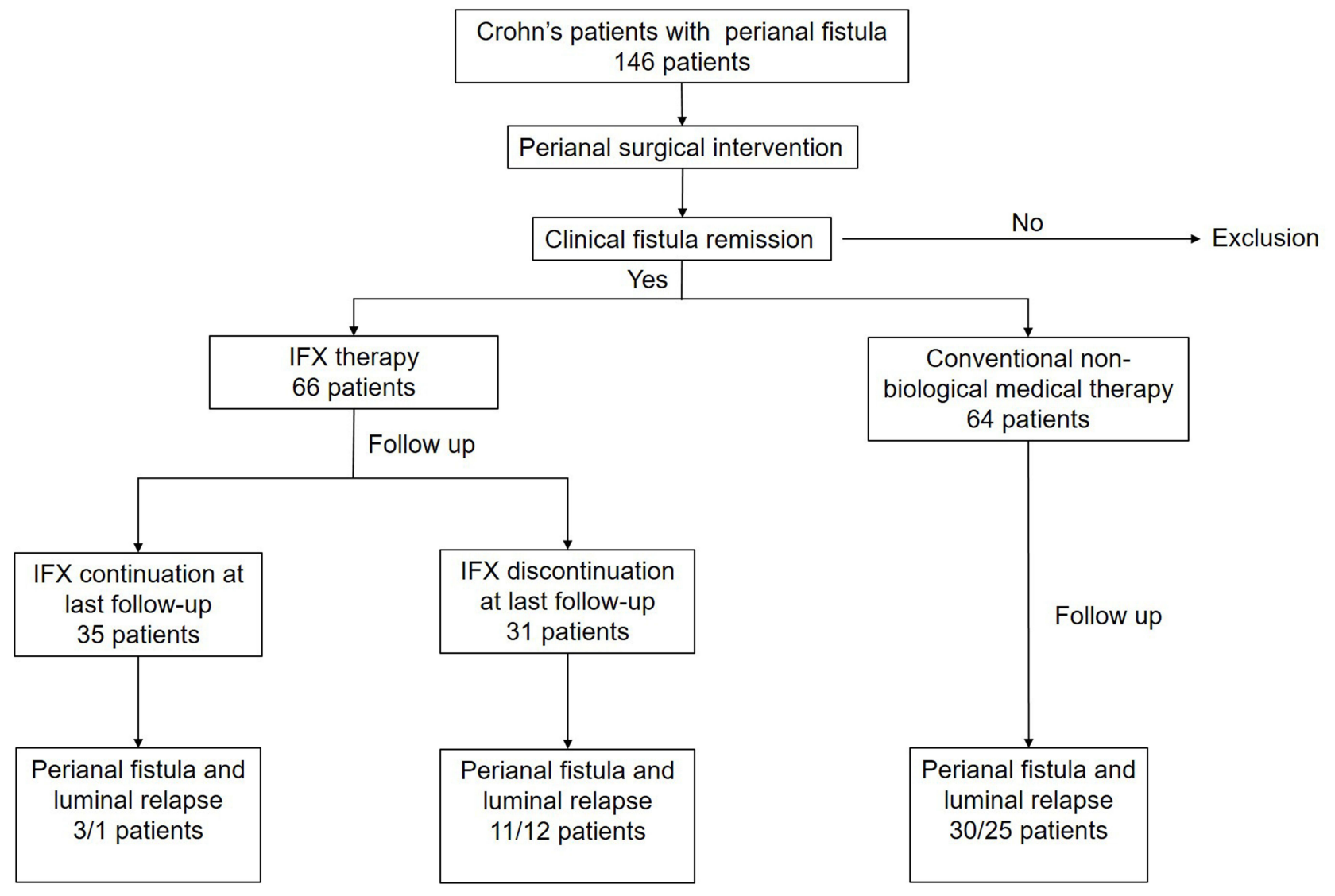

Figure I Flowchart of study and follow-up procedure.

a fistula that was high in position with multiple external openings and manifested with perianal abscesses, rectovaginal fistulas or anorectal strictures.

Two groups were analysed: patients in the IFX group received IFX at a dose of $5 \mathrm{mg} / \mathrm{kg}$ at weeks 0,2 and 6 as induction therapy and every 8 weeks as maintenance therapy, and the control group received conventional nonbiological medical therapy (5-ASA, thalidomide or immunosuppressants). The following data were recorded: age, sex, disease duration, smoking history, CD phenotypes, types of perianal fistula, laboratory information including leucocyte count and C-reactive protein at the time of receiving medical treatment after surgery. For IFX treatment, the date of the first infusion and the number of infusions were recorded. Combination therapy was defined as the use of conventional immunosuppressants combined with an anti-TNF agent. Perianal surgeries, including drainage of the perianal abscess, seton insertion, fistulotomy, proctectomy/proctocolectomy and defunctioning surgery, were recorded in this study.
This study was approved by the Ethics Committee of the Second Xiangya Hospital, Central South University (L2019064). It was conducted in accordance with the Declaration of Helsinki. All of the patient information was confidential, and all patients signed informed consent prior to enrolment. Patients under 18 years of age were enrolled with informed consent from the child's legal guardians.

\section{Assessment of Outcome}

The primary outcome was the rate of perianal relapse defined as a recurrence of fistula drainage or an abscess related to a previously treated fistula or a new fistula track. The secondary outcome was a relapse of luminal CD, defined as worsening of symptoms with a Crohn's disease activity index of $\geq 150$ points or aggravated endoscopic mucosal inflammation, and the number of perianal CD patients requiring proctectomy/proctocolectomy and defunctioning surgery.

\section{Statistical Analysis}

Patient characteristics are described as percentiles or medians. Qualitative and quantitative differences between 
subgroups were analysed using chi-squared or Fisher's exact tests for categorical parameters. The cumulative probabilities of survival without recurrence of perianal fistula and luminal CD were analysed using the KaplanMeier method. We used multivariate analysis with a Cox regression model to examine factors associated with relapse of perianal $\mathrm{CD}$ in patients with IFX discontinuation. $\mathrm{P}<0.05$ was considered statistically significant. Statistical analysis was performed using Statistical Product and Service Solutions (SPSS version 22.0).

\section{Results}

\section{Study Population}

From January 2013 to January 2019, a total of 146 patients had undergone perianal surgical interventions (PSIs) for PCD. Five patients were excluded because they received fewer than 3 IFX infusions, 6 patients were excluded because of an absence of fistula remission within 2 months after PSI, and 5 patients were excluded because of inaccurate information, including smoking history, dates of surgery and type of perianal fistula. Baseline clinical assessment showed that 64 patients received nonbiological medications after PSI, 66 patients were treated with IFX therapy, and 28 patients received combination therapy. The median follow-up was 62 months (IQR: 28-117 months). A total of $62.3 \%$ (81 of 130) of the fistulas were complex, and $5.4 \%$ ( 7 of 130) were rectovaginal fistulas. A noncutting draining seton was used in $51(39.2 \%)$ fistulas, and fistulotomy was used for 39 (30\%) fistulas. The median duration of IFX use before discontinuation was 6 months (IQR: 3-12 months), and IFX treatment was still ongoing for 35 of 66 patients at the last followup. When comparing the patients receiving IFX or not after PSI, there was no significant difference in sex, age, CD phenotype, type of perianal fistula, or type of fistula surgery, while a higher rate of fistula relapse was observed in the non-IFX-treated group $(p=0.002$, Table 1).

\section{Relapse of Perianal CD in Patients After Surgical Induced Remission}

Perianal relapse occurred in 30 of 64 nonbiological medication-treated cases and in 14 of 66 cases in the IFX therapy group. The median time to perianal relapse in the nonbiological treatment group was clearly shorter than that
Table I Baseline Characteristics of Perianal Crohn's Disease (PCD) Patients Treated by Non-Biological Medications or Infliximab

\begin{tabular}{|c|c|c|c|}
\hline Clinical Characteristics & $\begin{array}{l}\text { Patients with } \\
\text { Non-Biological } \\
\text { Therapy After } \\
\text { PSI }(n=64)\end{array}$ & $\begin{array}{l}\text { Patients } \\
\text { with IFX } \\
\text { Therapy } \\
\text { After } \\
\text { PSI }(n=66)\end{array}$ & $P$ value \\
\hline Gender (male) (\%) & $53(82.8)$ & $58(87.9)$ & 0.414 \\
\hline Age(y) & $27.9(17-49)$ & $24(17-45)$ & 0.345 \\
\hline Smoking history(\%) & $17(26.6)$ & $18(12.1)$ & 0.927 \\
\hline Disease location(\%) & & & 0.301 \\
\hline LI & $13(20.3)$ & $10(15.2)$ & \\
\hline L2 & $22(34.3)$ & $23(34.8)$ & \\
\hline L3 & $18(28.1)$ & $27(40.9)$ & \\
\hline L4 & $11(17.2)$ & $6(9.1)$ & \\
\hline Perianal only & $3(4.7)$ & $4(6)$ & 0.729 \\
\hline Disease phenotype(\%) & & & 0.095 \\
\hline BI & $23(35.9)$ & $28(42.4)$ & \\
\hline B2 & $35(54.7)$ & $25(37.9)$ & \\
\hline B3 & $6(9.4)$ & $13(19.7)$ & \\
\hline Proctitis(\%) & $35(54.7)$ & $41(62.1)$ & 0.496 \\
\hline $\begin{array}{l}\text { Interval between } \\
\text { surgery and medication } \\
\text { administration(d) }\end{array}$ & $34(21-48)$ & $33(14-50)$ & 0.367 \\
\hline Prior anti-TNF exposure(\%) & $3(4.7)$ & $7(10.6)$ & 0.205 \\
\hline Complex fistula(\%) & $4 I(64.1)$ & $40(60.6)$ & 0.684 \\
\hline Recto-vaginal fistula(\%) & $4(6.3)$ & $3(4.5)$ & 0.667 \\
\hline Seton (\%) & $22(34.3)$ & $29(43.9)$ & 0.264 \\
\hline Fistulotomy(\%) & $20(31.3)$ & $19(28.8)$ & 0.544 \\
\hline Seton plus fistulotomy(\%) & $15(23.4)$ & $\mathrm{II}(16.7)$ & 0.335 \\
\hline Rectal advancement flap(\%) & $3(4.7)$ & $2(3)$ & 0.623 \\
\hline $\begin{array}{l}\text { Ligation of the intersphincteric } \\
\text { fistula tract(\%) }\end{array}$ & $4(6.3)$ & $5(7.6)$ & 0.766 \\
\hline WBC(\%) & $7.3(2.97-13.5)$ & $\begin{array}{l}8.03(3.53- \\
13.4)\end{array}$ & 0.5 \\
\hline CRP(\%) & $38.75(1-110.4)$ & $\begin{array}{l}46.36(2.04- \\
222)\end{array}$ & 0.481 \\
\hline Combination therapy(\%) & & 28 & \\
\hline Perianal fistula relapse(\%) & $30(46.9)$ & $14(21.2)$ & 0.002 \\
\hline
\end{tabular}

Note: Data are presented as $n(\%)$ or median (25th-75th percentile).

Abbreviations: PSI, perianal surgical intervention; IFX, infliximab; WBC, white blood cell count; CRP, C-reactive protein. 


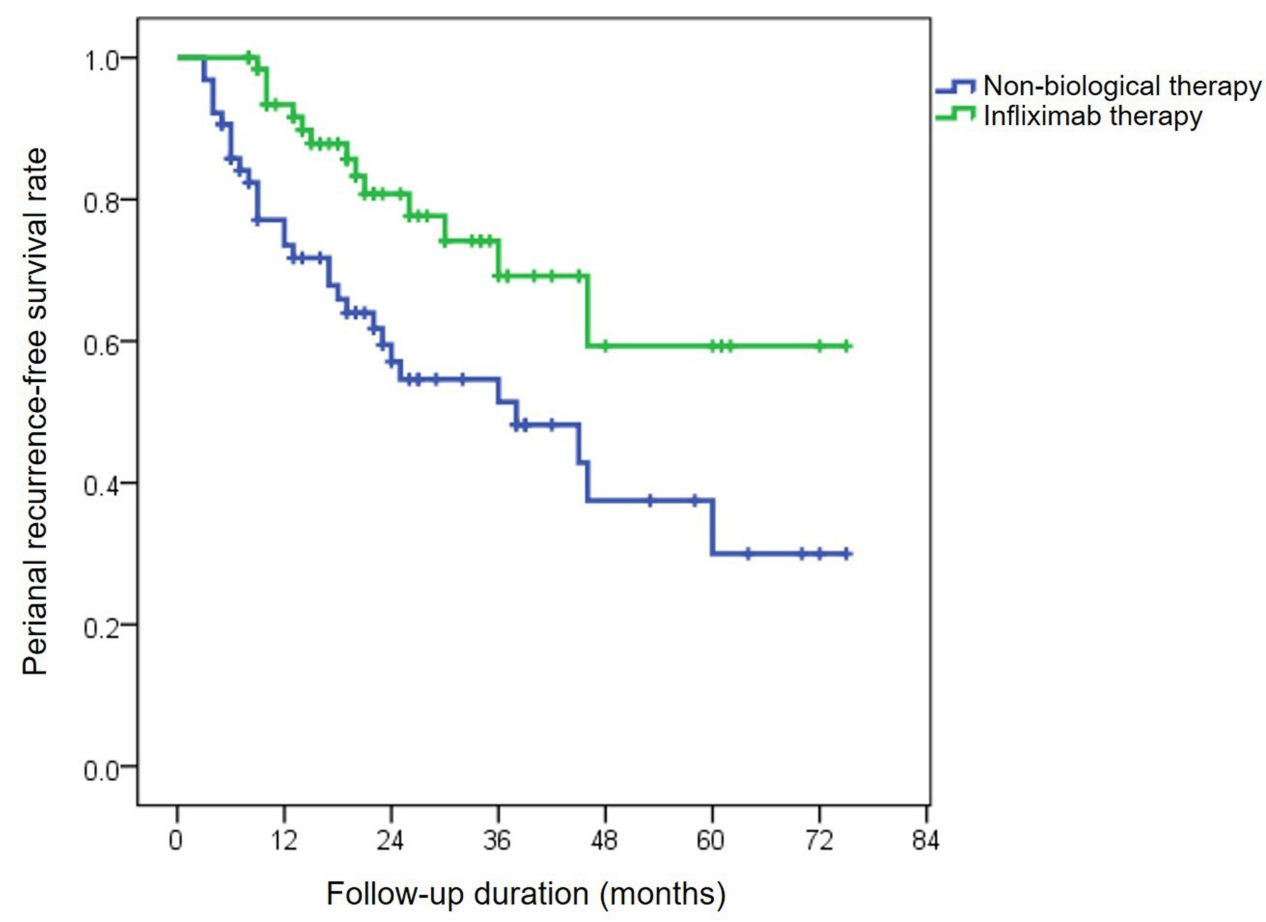

Figure 2 Cumulative probabilities of perianal relapse-free survival in patients treated with nonbiological medications or infliximab using the Kaplan-Meier method.

in the IFX-treated group (12 months versus 17 months, $p<0.0001)$. The cumulative probabilities of perianal relapse-free survival in patients with nonbiological treatment were $77.1 \%$ at 1 year, $54.6 \%$ at 3 years, and $30 \%$ at 5 years. Concomitantly, rates of perianal relapse-free period in the IFX-treated group were $91.6 \%, 69.2 \%$, and $59.3 \%$ at 1,3 and 5 years, respectively ( $p=0.004$, Figure 2 ).

\section{Relapse of Luminal CD in Patients After Perianal Surgery}

Of the 86 remaining free of perianal relapse, luminal CD relapse occurred in 25 of 64 (39\%) patients who received nonbiological medical therapy and 13 of 66 (19.7\%) taking IFX. The cumulative probabilities of without luminal CD relapse in IFX treatment were $92.3 \%, 74.2 \%$ and $68.5 \%$ at 1,3 and 5 years, respectively, and the luminal CD recurrence-free survival rates in patients with nonbiological medical therapy were $90.6 \%, 59.4 \%$, and $25.7 \%$ at 1,3 and 5 years, respectively ( $p=0.03$, Figure 3 ).

During the follow-up period, 10 of $64(15.6 \%)$ patients without IFX therapy required defunctioning surgery (6 ileostomy and 4 colostomy), and one underwent proctectomy. Additionally, 2 patients (3\%) who received IFX treatment required a colostomy.

\section{Predictive Factors of PCD Relapse After PSI}

We next determined the factors associated with perianal relapse in IFX-treated patients. In multivariate analysis, factors independently associated with fistula relapse in patients treated by IFX were a penetrating CD phenotype vs nonpenetrating nonstricturing ( $\mathrm{OR}=4.324 ; 95 \% \mathrm{CI}$ : 1.269-14.73, $\mathrm{p}=0.019)$ and complex fistula vs simple fistula $(\mathrm{OR}=3.392 ; 95 \% \mathrm{CI}: 1.158-9.936, \mathrm{p}=0.026)$. As shown in Figure 4, discontinuation of IFX therapy during follow-up significantly increased the risk of fistula relapse $(\mathrm{OR}=2.43$; 95\% CI: 1.061-5.565, $\mathrm{p}=0.036)$. In addition, $\mathrm{CD}$ location and combination therapy with immunosuppressants were not predictors of perianal CD relapse (Table 2).

\section{Discussion}

Perianal fistulas develop in $40 \%$ of CD patients and are difficult to treat; reduced quality of life and a higher rate of perianal fistulas have been reported in East Asian CD patients. ${ }^{2,20}$ Limited studies have focused on the outcomes of PCD after perianal surgical intervention. In this retrospective study, we found that the cumulative probabilities of perianal relapse-free survival in patients treated with nonbiological medical therapy after surgery were $77.1 \%$ at 


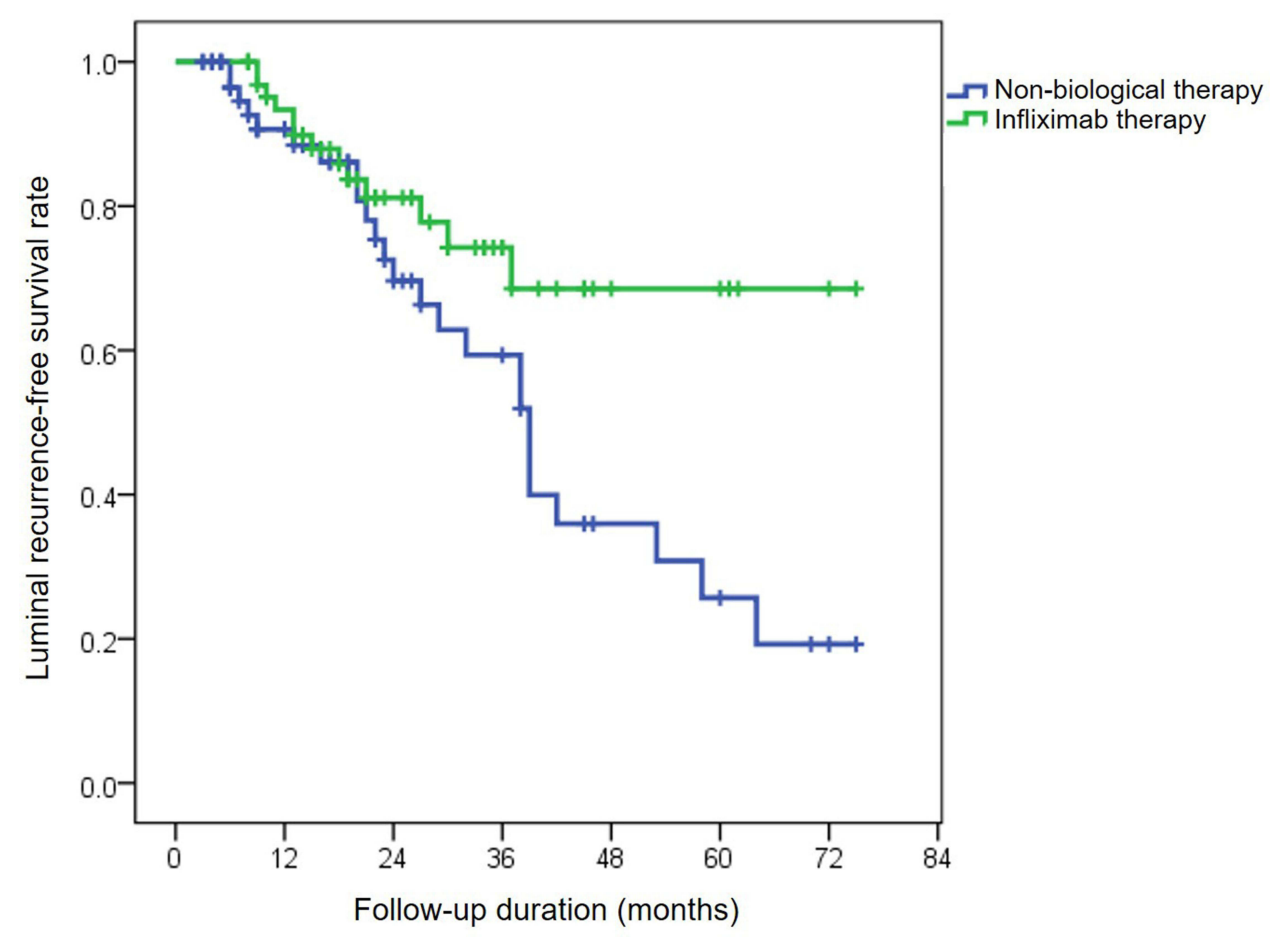

Figure 3 Rate of survival without luminal relapse in patients treated with nonbiological medications or infliximab using Kaplan-Meier analysis.

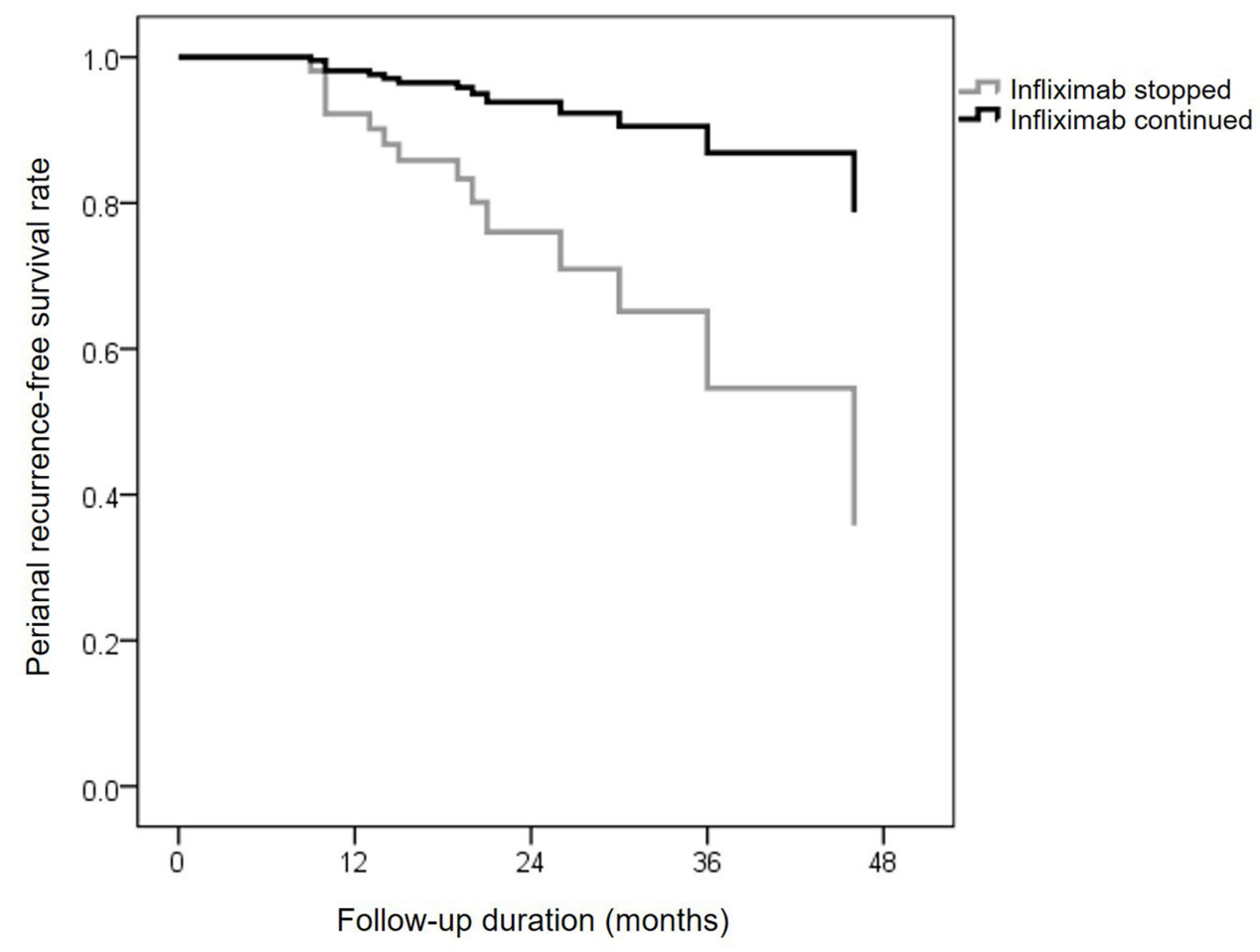

Figure 4 Perianal recurrence-free survival following infliximab therapy discontinuation with a multivariate Cox regression model.

1 year, $54.6 \%$ at 3 years, and $30 \%$ at 5 years. IFX treatment significantly reduced the risk of perianal and luminal recurrence compared with nonbiological therapy.
The management of perianal fistula $\mathrm{CD}$ is a difficult challenge in the clinic. Biological agents dramatically reduced the development of PCD and the risk of surgical 
Table 2 Multivariable Cox Regression Analysis in Predicting Factors for Perianal Crohn's Disease Relapse After Discontinuation of Infliximab

\begin{tabular}{|l|l|r|}
\hline Variable & Odds Ratio (95\% CI) & P value \\
\hline Gender & $0.077(0.005-1.16)$ & 0.064 \\
\hline Disease location & & \\
\hline LI-ileal & - & - \\
\hline L2-ileocolonic & $0.115(0.003-5)$ & 0.26 I \\
\hline L3-colonic & $0.68(0.035-13.231)$ & 0.799 \\
\hline L4-upper digestive tract & $0.307(0.012-7.766)$ & 0.474 \\
\hline Disease phenotype & & - \\
\hline BI-non-penetrating non- & - & \\
\hline stricturing & & 0.302 \\
\hline B2-stricturing & $0.55(0.176-1.7 I 1)$ & 0.019 \\
\hline B3-penetrating & $4.324(1.269-14.73)$ & 0.026 \\
\hline Complex fistula & $3.392(1.158-9.936)$ & 0.036 \\
\hline IFX therapy discontinuation & $2.43(1.061-5.565)$ & 0.7 \\
\hline Chemotherapy & $0.736(0.155-3.49 I)$ & \\
\hline
\end{tabular}

Abbreviation: IFX, infliximab.

resection; ${ }^{10}$ however, approximately $54 \%$ of patients who received IFX maintenance therapy for PCD stop responding after 54 weeks of follow-up. ${ }^{21}$ Meanwhile, the cumulative rates of 5-year perianal fistula relapse and perianal surgery were not significantly decreased when using biologic agents. ${ }^{22,23}$ Surgical intervention is indispensable for the drainage of septic complications. ${ }^{22}$ A total of $46.1 \%$ of PCD patients received surgery as the first-line therapy in an Indian study. ${ }^{24}$ In this study, we observed the outcomes of PCD patients after perianal surgery in a Chinese-based population and found that the cumulative probabilities of perianal relapse in IFX-treated patients were significantly lower than those in patients with nonbiological therapy at the 1-, 3- and 5-year follow-ups ( $8.4 \%$ vs $22.9 \%, 30.8 \%$ vs $45.4 \%, 40.7 \%$ vs $70 \%, \mathrm{p}=0.004)$. This was similar to the $40.1 \%$ of patients who experienced fistula recurrence after a combination of IFX and non-cutting seton therapy at 5 years. $^{3}$

Seton treatment should not be recommended as the sole treatment for perianal Crohn's fistulas. ${ }^{25}$ In contrast, the use of immunomodulators alone and anti-TNF $\alpha$ alone reduced the risk of PCD development after 2 years by $52 \%$ and $47 \%,{ }^{26}$ respectively. Our study showed that biological therapy concomitant with perianal intervention could significantly decrease fistula recurrence in perianal CD patients compared with conventional medication with surgery. These results are consistent with a study that reported that anti-TNFs along with a surgical approach can reduce the need for repeat surgery and result in improved outcomes in PCD patients. ${ }^{27}$ The overall improvement in patients who underwent surgery alone was $35.9 \%$ vs $71.3 \%$ in patients who received surgery and biological treatment. ${ }^{28}$

Because of the high cost of biologics and the lack of insurance coverage in China, the rate of biological therapy in PCD patients is low. Only $13.5 \%$ of PCD patients in Hong Kong receive biological therapy within the first year of a PCD diagnosis. ${ }^{2}$ In our study, anti-TNF agents were discontinued in 31 of 66 (47\%) PCD patients who initiate IFX treatment. We also observed luminal relapse-free rates of $92.3 \%, 74.2 \%$ and $68.5 \%$ of infliximab-treated patients at 1,3 and 5 years, respectively. This result differed from that reported in the prospective cohort study by Audrey et al, which showed that $97 \%, 87 \%$ and $84 \%$ of PCD patients were free of luminal recurrence at 1,3 and 5 years, ${ }^{17}$ suggesting a shorter duration of anti-TNFs use among PCD patients in China than in European countries.

In patients with perianal fistulizing Crohn's disease who have achieved symptomatic response on anti-TNF therapy, the continued use of anti-TNF therapy was required to achieve and maintain complete remission. Moreover, as fistulas are a high risk factor for poor longterm outcomes, treatment of PCD could strive for complete remission. ${ }^{29}$ The short-term use of anti-TNFs in combination with surgery did not significantly improve the long-term outcomes of PCD patients. Only 18\% of patients achieved sustained clinical fistula healing after 21 months of follow-up when infliximab was administered via 3 infusions (at 0,2 , and 6 weeks) without maintenance therapy. ${ }^{30}$ Half of the fistulising CD patients experienced a fistula relapse after biological therapy was discontinued, ${ }^{23}$ and more than 1 year of anti-TNF treatment is recommended in association with surgery. ${ }^{31}$ These results also supported our study that discontinuation of IFX therapy during follow-up had a 2.4-fold increase in risk of fistula relapse. We also analyzed other factors associated with perianal relapse in PCD patients using anti-TNF after PSI. Importantly, we found complex fistula was an independent risk factor associated with perianal relapse. Patients with simple fistula always present with a high rate of deep remission as observed on magnetic 
resonance imaging (MRI). The complex fistula has multiple and/or branching fistula tracts, rectovaginal fistula and/ or fistulas associated with active rectal disease or anal stenosis, always required combined medical therapy (at least one biologic drug) and surgical interventions such as advancement flaps, ligation of the intersphincteric fistula tract, defunctioning stoma or proctectomy. ${ }^{32}$ Half of the patients with a complex fistula eventually require a proctocolectomy or proctectomy. ${ }^{33} \mathrm{We}$ also found an increased risk of perianal recurrence in patients with a penetrating phenotype. This finding is supported by a 10year follow-up study from Denmark that reported that penetrating behaviour increased the risk of PCD development. ${ }^{5}$ There is a strong association between perianal and non-perianal fistulizing disease. Tang et al reported that $14 \%$ of patients with only perianal disease, approximately $10 \%$ with isolated luminal fistulas, whereas almost $8 \%$ had both phenotypes. ${ }^{34}$ This association is stronger in Crohn's colitis than that limited to the small bowel. ${ }^{35}$ Conversely, another study reported that a stricturing phenotype was significantly associated with fistula relapse in PCD patients after surgery. ${ }^{17}$ Unexpectedly, there was no difference between combination therapy and IFX alone in preventing perianal relapse in patients who achieved a remission after surgery in our research. Similar results were reported in a prospective study of 78 perianal CD patients, which found that maintenance therapy with immunosuppressants was not associated with a reduced risk of perianal relapse. ${ }^{36}$ This is comparable to the finding by Pauline et al, who demonstrated that $84 \%$ of patients sustained a perianal response after IFX discontinuation at 18 months. ${ }^{37}$ A prospective study also showed that maintenance of immunosuppressants after anti-TNF discontinuation was associated with perianal relapse $(\mathrm{HR}=0.3){ }^{23}$

Our study included a large number of perianal CD patients with long-term follow-up in China. Expensive drugs and a lack of medical insurance in China have made the treatment of PCD a great challenge. There were several limitations in this research. First, the definition of fistula remission after perianal surgery did not include MRI in all patients. The complete remission was defined as clinical and radiographic remission. Radiological healing was recently regarded as a goal for patients with fistulising $\mathrm{CD}$, and it lagged behind clinical remission by a median of 12 months. ${ }^{38}$ MRI and endoscopic ultrasound(EUS) are accurate for the detection and classification of fistulas and are recommended in patients with suspicion of active fistulizing disease to delineate the anatomy of the fistula. ${ }^{39}$ The use of MRI or EUS to guide therapy in patients with CD perianal fistulas is associated with improved short- and long-term symptomatic response rates. ${ }^{39} \mathrm{Ng}$ et al demonstrated that persistent active tracks on MRI still existed in $71 \%$ of patients treated with IFX at a median of 36 weeks of follow-up. Moreover, of 26 PFCD patients treated with anti-TNFs in this study, MRI showed complete healing $(20,28$, and $30 \%$, respectively), improvement $(68,72$, and $65 \%)$ and no change $(12,0$, and $0 \%$ at 6,12 , and 18 months, respectively. ${ }^{40}$ Another study also investigated whether $35.3 \%$ of patients who received radiological remission developed relapse at a median of 6 months after stopping anti-TNF therapy, ${ }^{36}$ showing that radiological assessment before stopping anti-TNF therapy is critical for perianal CD. Second, IFX drug levels were not assessed during the follow-up. High infliximab levels are associated with perianal fistula healing and closure in CD. A total of 117 patients were analysed, and patients with fistula healing had higher serum infliximab levels than those with active fistulas (15.8 vs $4.4 \mu \mathrm{g} / \mathrm{mL}$ ). A trough level higher than $7.1 \mu \mathrm{g} / \mathrm{mL}$ was identified as the optimal trough level of infliximab for fistula healing. ${ }^{41}$ In a similar study, patients with fistula healing had higher levels of infliximab than those without fistula healing (8.1 vs $3.2 \mu \mathrm{g} / \mathrm{mL}){ }^{42}$ Additionally, IFX drug levels of $9.25 \mu \mathrm{g} /$ $\mathrm{m}$ at week 2 and $7.25 \mu \mathrm{g} / \mathrm{m}$ at week 6 were the best predictors of fistula response at weeks 14 and $30 .{ }^{43}$ Third, in patients received seton placement, although it is recommended to keep the seton in place until at least the induction of the anti-TNF treatment period has been completed. ${ }^{44}$ Their setons removed mainly according to individual decisions instead of rigid proctoscopies that demonstrated absence of rectal inflammation, resulting this sample heterogeneous in some aspects. Fourth, the information about the use of antibiotic therapy among patients after perianal surgeries were lacked, as the use of antibiotics (metronidazole and ciprofloxacin) are recommended for initial management to achieve symptomatic response and may contribute to fistula healing. ${ }^{39}$ Last, because the study had a long inclusion period according to the evolving guidelines, the debate about optimal strategies for the management of PCD and a lack of effective definitive surgical procedures for PCD resulted in a high rate of perianal fistula relapse in our study.

In summary, in the present study, the rate of perianal relapse in patients in China achieving remission after 
perianal surgery with infliximab at 5 years was $40.7 \%$ compared with $70 \%$ in those with nonbiological therapy. For infliximab therapy, discontinuation of IFX use, a penetrating phenotype and complex fistulas were associated with an increased risk of perianal relapse.

\section{Data Sharing Statement}

The data used to support the findings of this study are available from the corresponding author upon request.

\section{Author Contributions}

All authors made a significant contribution to the work reported, in the conception, study design, execution, acquisition of data, analysis and interpretation, or in all of these areas; took part in drafting, revising or critically reviewing the article; gave final approval of the version to be published; have agreed on the journal to which the article has been submitted; and agreed to be accountable for all aspects of the work.

\section{Funding}

This study was sponsored by the National Natural Science Foundation of China (No. 81900478) and the Natural Science Foundation of Hunan Province (No. 2020JJ5801), China.

\section{Disclosure}

The authors report no conflicts of interest in this work.

\section{References}

1. Ng SC, Shi HY, Hamidi N, et al. Worldwide incidence and prevalence of inflammatory bowel disease in the 21 st century: a systematic review of population-based studies. The Lancet. 2017;390(10114):2769-2778. doi:10.1016/S0140-6736(17)32448-0

2. Mak WY, Mak OS, Lee CK, et al. Significant medical and surgical morbidity in perianal crohn's disease: results from a territory-wide study. J Crohns Colitis. 2018;12:1392-1398. doi:10.1093/ecco-jcc /jjx 180.915

3. Bouguen G, Siproudhis L, Gizard E, et al. Long-term outcome of perianal fistulizing Crohn's disease treated with infliximab. Clin Gastroenterol Hepatol. 2013;11(975-81):e1-4. doi:10.1016/j.cgh.20 12.12.042

4. Lee JB, Yoon SG, Park KJ, et al. The clinical features and predictive risk factors for reoperation in patients with perianal crohn diseases; a multi-center study of a korean inflammatory bowel disease study group. Ann Coloproctol. 2015;31:176-181. doi:10.3393/ac.2015. 31.5.176

5. Zhao M, Lo BZS, Vester-Andersen MK, et al. A 10-Year follow-up study of the natural history of perianal Crohn's Disease in a Danish population-based inception cohort. Inflamm Bowel Dis. 2019;25: 1227-1236. doi:10.1093/ibd/izy374

6. Sandborn WJ, Fazio VW, Feagan BG, et al. AGA technical review on perianal Crohn's disease. Gastroenterology. 2003;125:1508-1530. doi:10.1016/j.gastro.2003.08.025
7. Kotze PG, Shen B, Lightner A, et al. Modern management of perianal fistulas in Crohn's disease: future directions. Gut. 2018;67:1181-1194. doi:10.1136/gutjnl-2017-314918

8. Gecse KB, Bemelman W, Kamm MA, et al. A global consensus on the classification, diagnosis and multidisciplinary treatment of perianal fistulising Crohn's disease. Gut. 2014;63:1381-1392. doi:10. 1136/gutjnl-2013-306709

9. Herissay A, Siproudhis L, Le Balc'h E, et al. Combined strategies following surgical drainage for perianal fistulizing Crohn's disease: failure rates and prognostic factors. Colorectal Dis. 2020. 23 (1):159-168.

10. Park SH, Aniwan S, Scott Harmsen W, et al. Update on the natural course of fistulizing perianal Crohn's disease in a population-based cohort. Inflamm Bowel Dis. 2019;25:1054-1060. doi:10.1093/ibd/ izy329

11. Present DH, Rutgeerts $\mathrm{P}$, Targan S, et al. Infliximab for the treatment of fistulas in patients with Crohn's disease. $N$ Engl J Med. 1999;340 (18):1398-1405. doi:10.1056/NEJM199905063401804

12. Laharie D, Mesli S, El Hajbi F, et al. Prediction of Crohn's disease relapse with faecal calprotectin in infliximab responders: a prospective study. Aliment Pharmacol Ther. 2011;34(4):462-469. doi:10.1111/j.1365-2036.2011.04743.x

13. Ford AC, Sandborn WJ, Khan KJ, et al. Efficacy of biological therapies in inflammatory bowel disease: systematic review and meta-analysis. Am J Gastroenterol. 2011;106:644-59,quiz 660. doi:10.1038/ajg.2011.73

14. Louis E, Mary JY, Vernier-Massouille G, et al. Maintenance of remission among patients with Crohn's disease on antimetabolite therapy after infliximab therapy is stopped. Gastroenterology. 2012;142:63-70.e5; quiz e31.

15. Louis E, Mary JY, Vernier-Massouille G, et al. Maintenance of remission among patients with Crohn's disease on antimetabolite therapy after infliximab therapy is stopped. Gastroenterology. 2012;142:63-70e5; quiz e31. doi:10.1053/j.gastro.2011.09.034

16. Chhaya V, Saxena S, Cecil E, et al. Emerging trends and risk factors for perianal surgery in Crohn's disease: a 20 -year national population-based cohort study. Eur $J$ Gastroenterol Hepatol. 2016;28:890-895. doi:10.1097/MEG.0000000000000651

17. Malian A, Riviere P, Bouchard D, et al. Pedictors of perianal fistula relapse in Crohn's disease. Inflamm Bowel Dis. 2020;26:926-931. doi:10.1093/ibd/izz200

18. Gomollon F, Dignass A, Annese V 3rd, et al. European evidencebased consensus on the diagnosis and management of Crohn's disease 2016: part 1: diagnosis and medical management. J Crohns Colitis. 2017;11:3-25. doi:10.1093/ecco-jcc/jjw168

19. Lamb CA, Kennedy NA. British Society of Gastroenterology consensus guidelines on the management of inflammatory bowel disease in adults. Gut. 2019;68:s1-s106.

20. Kochar B, Barnes EL, Herfarth HH, et al. Asians have more perianal Crohn disease and ocular manifestations compared with white Americans. Inflamm Intest Dis. 2018;2:147-153. doi:10.1159/ 000484347

21. Sands BE, Anderson FH, Bernstein CN, et al. Infliximab maintenance therapy for fistulizing Crohn's disease. $N$ Engl $J$ Med. 2004;350:876-885. doi:10.1056/NEJMoa030815

22. Sun XL, Chen SY, Tao SS, et al. Optimized timing of using infliximab in perianal fistulizing Crohn's disease. World J Gastroenterol. 2020;26:1554-1563. doi:10.3748/wjg.v26.i14.1554

23. Legue C, Brochard C, Bessi G, et al. Outcomes of perianal fistulising crohn's disease following Anti-TNFalpha treatment discontinuation. Inflamm Bowel Dis. 2018;24:1107-1113. doi:10.10 93/ibd/izy008

24. Vuyyuru SK, Sahu P, Kedia S, et al. Long-term outcomes in perianal fistulizing Crohn's disease in a resource-limited setting: a cohort analysis. Indian J Gastroenterol. 2020;39:435-444. doi:10.1007/ s12664-020-01054-7 
25. Wasmann KA, de Groof EJ, Stellingwerf ME, et al. Treatment of perianal fistulas in Crohn's Disease, Seton versus anti-TNF versus surgical closure following Anti-TNF [PISA]: a randomised controlled trial. J Crohns Colitis. 2020;14(8):1049-1056. doi:10.1093/ecco-jcc /jjaa004

26. Adler J, Lin CC, Gadepalli SK, et al. Association between steroid-sparing therapy and the risk of perianal fistulizing complications among young patients with Crohn disease. JAMA Netw Open. 2020;3(6):e207378. doi:10.1001/jamanetworkopen.2020.7378

27. Sebastian S, Black C, Pugliese D, et al. The role of multimodal treatment in Crohn's disease patients with perianal fistula: a multicentre retrospective cohort study. Aliment Pharmacol Ther. 2018;48:941-950. doi:10.1111/apt.14969

28. El-Gazzaz G, Hull T, Church JM. Biological immunomodulators improve the healing rate in surgically treated perianal Crohn's fistulas. Colorectal Dis. 2012;14(10):1217-1223. doi:10.1111/j.14631318.2012.02944.x

29. Schwartz DA, Loftus EV Jr., Tremaine WJ, et al. The natural history of fistulizing Crohn's disease in Olmsted County, Minnesota. Gastroenterology. 2002;122:875-880. doi:10.1053/gast.2002.32362

30. Hyder SA, Travis SP, Jewell DP, et al. Fistulating anal Crohn's disease: results of combined surgical and infliximab treatment. Dis Colon Rectum. 2006;49:1837-1841. doi:10.1007/s10350-006-0656-5

31. Bor R, Farkas K, Balint A, et al. Efficacy of combined anti-TNFalpha and surgical therapy in perianal and enterocutaneous fistulizing Crohn's disease-clinical observations from a tertiary Eastern European center. Scand J Gastroenterol. 2015;50:182-187. doi:10.3109/00365521.2014.936033

32. Adamina M, Bonovas S, Raine T, et al. ECCO guidelines on therapeutics in Crohn's Disease: surgical treatment. J Crohns Colitis. 2020;14:155-168. doi:10.1093/ecco-jcc/jjz187

33. Bell SJ, Williams AB, Wiesel $P$, et al. The clinical course of fistulating Crohn's disease. Aliment Pharmacol Ther. 2003;17:1145-1151. doi:10.1046/j.1365-2036.2003.01561.x

34. Tang LY, Rawsthorne P, Bernstein CN. Are perineal and luminal fistulas associated in Crohn's disease? A population-based study. Clin Gastroenterol Hepatol. 2006;4:1130-1134. doi:10.1016/j. cgh.2006.06.021
35. Hirten RP, Shah S, Sachar DB, et al. The management of intestinal penetrating Crohn's disease. Inflamm Bowel Dis. 2018;24:752-765. doi:10.1093/ibd/izx108

36. Mak JWY, Tang W, Yip TCF, et al. Stopping anti-tumour necrosis factor therapy in patients with perianal Crohn's disease. Aliment Pharmacol Ther. 2019;50:1195-1203. doi:10.1111/apt.15547

37. Roumeguere P, Bouchard D, Pigot F, et al. Combined approach with infliximab, surgery, and methotrexate in severe fistulizing anoperineal Crohn's disease: results from a prospective study. Inflamm Bowel Dis. 2011;17:69-76. doi:10.1002/ibd.21405

38. Tozer $\mathrm{P}, \mathrm{Ng} \mathrm{SC}$, Siddiqui $\mathrm{MR}$, et al. Long-term MRI-guided combined anti-TNF- $\alpha$ and thiopurine therapy for crohn's perianal fistulas. Inflamm Bowel Dis. 2012;18:1825-1834. doi:10.1002/ ibd. 21940

39. Steinhart AH, Panaccione R, Targownik L, et al. Clinical practice guideline for the medical management of perianal fistulizing Crohn's disease: the Toronto consensus. Inflamm Bowel Dis. 2019;25:1-13. doi:10.1093/ibd/izy247

40. Ng SC, Plamondon S, Gupta A, et al. Prospective evaluation of antitumor necrosis factor therapy guided by magnetic resonance imaging for Crohn's perineal fistulas. Am J Gastroenterol. 2009;10 4:2973-2986. doi:10.1038/ajg.2009.509

41. Plevris N, Jenkinson PW, Arnott ID, et al. Higher anti-tumor necrosis factor levels are associated with perianal fistula healing and fistula closure in Crohn's disease. Eur $J$ Gastroenterol Hepatol. 2020;32:32-37. doi:10.1097/MEG.0000000000001561

42. Yarur AJ, Kanagala V, Stein DJ, et al. Higher infliximab trough levels are associated with perianal fistula healing in patients with Crohn's disease. Aliment Pharmacol Ther. 2017;45:933-940. doi:10.1111/ apt.13970

43. Davidov Y, Ungar B, Bar-Yoseph H, et al. Association of induction infliximab levels with clinical response in perianal Crohn's disease. J Crohns Colitis. 2017;11:549-555.

44. Bemelman WA, Warusavitarne J, Sampietro GM, et al. ECCO-ESCP consensus on surgery for Crohn's Disease. J Crohns Colitis. 2018;12:1-16.
International Journal of General Medicine

\section{Publish your work in this journal}

The International Journal of General Medicine is an international, peer-reviewed open-access journal that focuses on general and internal medicine, pathogenesis, epidemiology, diagnosis, monitoring and treatment protocols. The journal is characterized by the rapid reporting of reviews, original research and clinical studies across all disease areas. The manuscript management system is completely online and includes a very quick and fair peer-review system, which is all easy to use. Visit http://www.dovepress.com/ testimonials.php to read real quotes from published authors. 